Published in final edited form as:

Adv Exp Med Biol. 2016 ; 916: 479-494. doi:10.1007/978-3-319-30654-4_21.

\title{
Zebrafish Germ Cell Tumors
}

\author{
Angelica Sanchez ${ }^{1,2}$ and James F. Amatruda ${ }^{1,2,3, \#}$ \\ ${ }^{1}$ Department of Pediatrics, University of Texas Southwestern Medical Center, 5323 Harry Hines \\ Boulevard, Dallas, Texas USA 75390 \\ ${ }^{2}$ Department of Molecular Biology, University of Texas Southwestern Medical Center, 5323 Harry \\ Hines Boulevard, Dallas, Texas USA 75390 \\ ${ }^{3}$ Department of Internal Medicine, University of Texas Southwestern Medical Center, 5323 Harry \\ Hines Boulevard, Dallas, Texas USA 75390
}

\section{Keywords}

Zebrafish; Primordial Germ Cell; Germ Cell Tumor; Seminoma; Non-seminoma

\section{Introduction}

Germ cell tumors (GCTs) are malignant cancers that arise from embryonic precursors known as Primordial Germ Cells. GCTs occur in neonates, children, adolescents and young adults and can occur in the testis, the ovary or extragonadal sites. Because GCTs arise from pluripotent cells, the tumors can exhibit a wide range of different histologies. Current cisplatin-based combination therapies cures most patients, however at the cost of significant toxicity to normal tissues. While GWAS studies and genomic analysis of human GCTs have uncovered somatic mutations and loci that might confer tumor susceptibility, little is still known about the exact mechanisms that drive tumor development, and animal models that faithfully recapitulate all the different GCT subtypes are lacking. Here we summarize current understanding of germline development in humans and zebrafish, describe the biology of human germ cell tumors, and discuss progress and prospects for zebrafish GCT models that may contribute to better understanding of human GCTs.

\section{Germline development in fish, mouse and human}

\section{Primordial Germ Cell (PGC) Specification}

The earliest cells of the germline lineage are known as Primordial Germ Cells (PGCs). PGC specification follows two distinct mechanisms, either preformation or induction, depending on the organism. Shortly after fertilization, zebrafish embryos, similar to C. elegans, Drosophila and Xenopus, contain preformed maternal RNA and proteins that are prepackaged in a cytoplasmic nuage, known as a germ plasm [1-4]. The germ plasm selectively and transcriptionally silences the expression of somatic genes while keeping the PGCs in a primitive pluripotent state. In flies and worms, RNA binding proteins including

\footnotetext{
\#correspondence to: james.amatruda@utsouthwestern.edu.
} 
Pumilio and Nanos contribute to this repression of somatic fate [5, 6]. In zebrafish, nanos is essential for the development of PGCs [5].

The identification of the zebrafish vasa ortholog greatly facilitated efforts to understand the development of the zebrafish germline [7-10]. Vasa is an RNA helicase that was previously shown to be a component of the germline in nematodes, flies and frogs [11-14]. In zebrafish, maternally produced vasa mRNA is localized to electron-dense material at the cleavage planes of embryos at the 4-cell stage. By the 4000-cell stage, four vasa-positive PGCs can be identified. These will undergo several rounds of proliferation to produce a population of 25 50 migrating PGCs that will form the gonad $[7,8,10,15]$.

In contrast to organisms with preformed germline components, in mice and humans PGCs are produced in the epiblast through a process known as induction. In response to signals produced in the extraembryonic ectoderm and visceral endoderm, including Bone Morphogenetic Proteins 2, 4 and 8b [16-19], some of the epiblast cells begin to express the marker Fragilis (also known as Mil-1/Ifitm3), signaling their competence to become germ cells [18, 20-26]. A few of these Fragilis-expressing cells will begin to express the transcriptional repressor Prdm1 (PR-domain-containing protein 1), also known as Blimp1 (Blymphocyte-induced maturation protein 1) [27]. Blimp1, along with Blimp14, acts to repress expression of somatic genes and maintain expression of pluripotency genes such as Stella, Oct3/4 and Nanog [20, 28-36].

\section{PGC Migration}

In nearly all metazoans, PGCs arise at sites distant from the future gonad and must migrate during embryogenesis to reach the proper location for eventual gonadogenesis [37-40]. In contrast to other organisms, zebrafish PGCs arise in four random locations with respect to the developmental axis of the embryo. The PGCs migrate to a series of intermediate targets, converging into bilateral clusters in the presomitic mesoderm, where the gonad will form [3, $10,15,41]$. This guided migration is orchestrated by an attractant gradient established by somatic expression of Stromal-derived factor 1 (sdf1a), also known as CXCL12 [42, 43]. The sdf1a ligand interacts with the chemokine receptor cxcr $4 \mathrm{~b}$ expressed on the surface of PGCs [42, 43]. This homing signal is further fine-tuned by the cxcr7 receptor on somatic cells, which acts as a repulsive guidance cue [44].

In mice and other mammals, the newly specified PGCs must travel from the primitive streak and localize to the endoderm around stage E7.5 [45, 46]. From E8 to E9.5 the PGCs migrate through the dorsal mesentery of the hindgut. Upon reaching the level of the gonadal ridges, the PGCs exit the hindgut in bilateral streams to populate the gonadal mesoderm [37, 46]. The c-Kit receptor and its ligand, KitL, are critical for the migration and survival of PGCs in mice [47-50].

\section{Germ cell differentiation}

Irrespective of the future sex of the animal, germ cells in zebrafish initially begin to differentiate into oocytes and are in a state known as juvenile hermaphroditism [51]. Upon the start of male germ cell differentiation, oocytes in male zebrafish undergo apoptosis as the mature male germline emerges [52]. Characterizations of male sex determination factors 
have identified several genes that are specific to the male gonads, such as anti-Mullerian hormone (amh) and sox 9a [53-55]. Furthermore, sox $9 a$ was shown to control juvenile hermaphroditism and regulate the transition to male fate producing mature sperm [56].

During gonadogenesis, the number and persistence of germ cells makes important contributions to sex determination [57, 58]. Several studies have revealed that lower PGC numbers promote male differentiation in zebrafish. Loss of dead end ( $d n d)$, an RNA-binding protein that is essential for PGC survival [59], leads to loss of all germ cells and male phenotypic differentiation [57, 60,61]. Similarly, loss of function ziwi, the zebrafish piwi homolog, leads to reduced numbers of germ cells and male phenotypic development [62]. Remarkably, Dranow and Draper found that adult female zebrafish depleted of germ cells due to loss-of-function mutations in nanos 3 convert to a male phenotype [58]. They concluded that a germ cell-derived signal acts on the somatic gonad to promote female development directly or indirectly by repressing male-specific gene expression.

In mice and other mammals, licensing is the initial step in which germ cells begin to differentiate into their respective sex cells dependent on the sex chromosomes present in the organism. This licensing event is initiated by the RNA-binding protein known as Deleted in azoospermia-like (DAZL); Dazl mutants no longer express sex specific markers and do not begin meiosis [63, 64]. During this transition, the germ cells are released from their transcriptional repression [65]. In prenatal males, presence of the SRY gene on the Y chromosome regulates expression of Sox 9 and is necessary for proper male gonadal development and spermatogenesis [66-68]. Humans with a heterozygous mutation in SOX9 develop a bone disorder known as campomelic dysplasia that is accompanied by gonadal sex reversal, while XY mice with homozygous mutations exhibit ovarian development [69-71]. These studies emphasized the importance of proper Sox 9 expression in testis development. To maintain male identity prenatally, Stra8 (Stimulated by retinoic acid gene 8), an enzyme required for meiosis initiation, must be persistently repressed by Cyp26B1 [72-74]. Postnatally, repression of Cyp26B1 releases repression of Stra8 and allows germ cells to respond to retinoic acid, which initiates meiosis [72-74]. The germ cells are now able to exit G1/G0 and can then proceed to make mature sperm.

As in the fish, gonadal sex in mammals appears not to be completely fixed. The transcription factor DMRT1 is required in both somatic cells and germ cells for normal male gonadal differentiation [75, 76]. Loss of Dmrt1 in adult Sertoli cells of the testis results in transformation of the cells to granulosa cells and transition of the gonad to a more ovarianlike phenotype [77]. Furthermore, forced expression of DMRT1 in the ovary reprograms granulosa cells to Sertoli cells, leading to the development of structures resembling seminiferous tubules [78].

\section{Human Germ Cell Tumors}

In humans, GCTs occur in infants, children and young adults [79] (Figure 1). Both childhood and adolescent/adult GCTs are thought to originate from Primordial Germ Cells (PGCs). Owing to the pluripotent nature of these cells, GCTs can take on a variety of different histologic fates [80]. GCTs in which the PGCs retain pluripotency and do not 
differentiate are known as seminomas (also called 'dysgerminomas' in females and 'germinomas' when occurring in the CNS). In contrast, GCTs in which the cells take on a variety of differentiation states are designated non-seminomas, of which embryonal carcinoma is thought to represent the stem cell component. GCTs differentiated to somatic cell lineages (endoderm, mesoderm, and ectoderm) are known as teratomas. Finally, GCTs may take on extraembryonic differentiation resembling the fetal yolk sac (yolk sac tumors) or the placenta (choriocarcinoma).

The histology of GCTs is similar in both males and females, whether occurring in the testis, ovary or extragonadal sites, implying origin from a common precursor cell [79]. However, there are some epidemiologic differences in the incidence of different types of GCT. In males there are two peaks of testicular GCT incidence, one in early childhood at age 3-4, and a second, much larger peak that begins at puberty and is maximal at around age 30 . In females, there is an early peak from age 0-2 representing the incidence of sacrococcygeal teratoma, an extragonadal GCT, in newborns and infants. Beginning at age 5-6, the incidence of ovarian GCT increases with age, becoming maximal at age 20-25 [81].

While the overall incidence of GCT (about 12,500 cases/year in the USA) is lower than that of common epithelial cancers such as lung, breast and prostate cancer, testicular GCT is the most common cancer and the leading cause of cancer death in young men [79]. The incidence of GCT is increasing around the world, for unknown reasons [81]. There are several known risk factors that increase the risk of developing testicular germ cell tumors. They include but are not limited to disorders of sexual development (DSD), gonadal dysgenesis, cryptorchidism (undescended testis), familial background, environmental exposure, and genetic association. Familial risk can increase the risk of developing GCT 4fold in a male with a father who had GCT or up to 9-fold in a male whose brother had GCTs. The incidence of GCT varies widely in different geographic regions [82, 83], leading to the idea that the environment may strongly influence risk for testicular GCT.

There are also important age-dependent differences in GCT histologic spectrum. Type I GCTs occur in infants and children and consist of teratomas and yolk sac tumors (YSTs). Type II tumors in adolescents and adults have more diverse histology, and include seminomas, non-seminomas or mixed tumors containing both seminomatous and nonseminomatous elements. Based on differing epidemiology, clinical outcome and histologic spectrum, GCTs in young children may be biologically distinct from GCTs occurring in older (post-pubertal) populations.

This idea is increasingly supported by molecular evidence. Whereas Type I tumors show variable Loss of Imprinting (LOI) at loci such as IGF2 and H19, adult-type GCTs tend to show complete erasure of imprinting $[84,85]$. This result is interesting, because it implies that Type I GCTs may arise at an earlier stage of PGC development, since PGCs undergo erasure of imprinting during early development, and this erasure is largely completed by the end of PGC migration. Cytogenetic data consistently show loss of Chromosome 1p and 6q in Type I tumors, while Type II tumors also commonly exhibit amplification of Chromosome 12p. More recently, studies directly comparing the gene expression patterns of pediatric and adult GCTs have demonstrated distinct transcriptional profiles in tumors of similar histology 
arising in different age groups (for example, in yolk sac tumors of children vs. yolk sac tumors of adolescent/adults) [86]. Taken together, these studies support the notion that different biological mechanisms may drive childhood and adolescent/adult germ cell tumorigenesis.

Current cisplatin-based therapy for GCTs cures most patients [81, 87, 88], but major challenges remain. $15 \%$ of patients have cisplatin-resistant tumors and will eventually die of their disease [89]. Furthermore, there is significant therapy-related toxicity in patients treated for GCTs. Late effects in patients treated with cisplatin, etoposide and bleomycin (the current first-line regimen for GCT) include pulmonary fibrosis [90], renal insufficiency and saltwasting [91-93], infertility and hormonal changes [94-98], hyperlipidemia [99, 100], Raynaud's phenomenon [91, 98, 101, 102], obesity [99, 100, 103-105] and neuropathy [106]. Ototoxicity results in significant hearing loss, as assessed by audiogram, in nearly $80 \%$ of patients [91, 97]. Survivors of GCT treatment have twice the risk of early onset cardiovascular disease [96] and second malignancies [107, 108].

Compared to many other solid malignancies, relatively few somatic mutations have been described in GCTs. This lack of knowledge inhibits the development of targeted therapy that could provide an alternative or adjunct to standard chemotherapy. Amplification of Chromosome 12p is a pathognomonic feature of adolescent/adult GCTs, but no genes in this region have definitively been linked to germ cell tumorigenesis [109]. The most commonly reported mutated gene is $K I T$, a tyrosine kinase growth factor receptor that plays important roles in germ cell development [110-115]. Mutations have also been reported in NRAS and $K R A S$, signaling components of the MAP kinase pathway that act downstream of KIT [116-119]. Central Nervous System GCTs exhibit KIT and $R A S$ mutations [120]. Somatic mutations in $B R A F$, another MAP kinase pathway member, have been associated with cisplatin resistance in adult TGCTs [121]. More recently, exome sequencing of TGCT identified somatic mutations in several genes including CIITA, NEB, PDGFRA, WHSC1 and $S U P T 6 H$ [122]. A larger study of 42 adult TGCTs identified somatic mutations in $C D C 27$ and mutations in $X R C C 2$ associated with cisplatin resistance [123]. To date, the mutation spectrum of Type I GCTs has not been reported.

A number of genome-wide association studies (GWAS) have been conducted in men with TGCT, resulting in the identification of a large number of novel germ cell tumor susceptibility loci. In 2009, two groups reported strong linkage of GCT susceptibility to loci on chromosomes 5, 6 and 12, suggesting roles for SPRY4 and KITLG, both components of receptor tyrosine kinase signaling, as well as for the pro-apoptotic $B A K 1$ gene $[124,125]$. A follow-up study by Turnbull and co-workers identified additional susceptibility loci near the DMRT1, TERT and ATF7IP genes [126]. The studies have subsequently been replicated in other patient populations [127-129]. More recently, further GWAS studies have identified new candidate GCT susceptibility loci, including genes with potential roles in telomere regulation, such as PITX1, or germ cell development, such as TEX14, RAD51C, PRDM14 and $D A Z L[130,131]$.

Because of the many unresolved issues concerning the causes and biological mechanisms of GCTs, and the urgent need to develop and test new treatments, animal models of GCT are 
badly needed. However, to date relatively few models have been available. The 129Sv inbred mouse strain was found more than 50 years ago to be susceptible to testicular teratoma formation, with spontaneous tumors forming in 1-5\% of animals [132]. Mutations in several genes have been shown to increase the teratoma incidence in 129Sv mice, including Dead end [133] and Dmrt1. In fact, Dmrt1-mutant 129Sv mice develop testicular teratomas at nearly $100 \%$ incidence $[134,135]$. The teratomas that develop in the 129Sv background strongly resemble the Type I testicular teratomas occurring in young boys. However, mouse models of seminomas or of non-seminomas other than Type I teratomas have not been described. Recent progress suggests that zebrafish may be a useful addition to GCT models, at least for seminomas.

\section{Zebrafish Germ Cell Tumor Models}

During the past several years, several fish models have been described with abnormal germline development that recapitulates certain aspects of human germ cell tumors. Three of these models were identified using the zebrafish, while one was identified in Medaka. All of these models demonstrate an inability to undergo proper germ cell differentiation and as a result exhibit immature, enlarged testes. Three of the models were identified through forward genetic N-ethyl-N-nitrosourea (ENU)-based mutagenesis screens while one is a transgenic line. These models can serve to provide further insight into human seminomas with the possibility to contribute to our understanding of the human disease.

The first fish model described was identified in Medaka, following an ENU mutagenesis screen to uncover genes that are important for germ cell and gonadal development [136]. Morinaga el al identified the hotei "hot" mutant fish, which was initially characterized as having extreme gonadal hypertrophy. The gonads were further examined and found to have increased numbers of germ cells that resided in disrupted testicular architecture, as well as decreased ability to produce mature sperm as compared with their wild-type siblings. The loss of function mutation was mapped, by positional cloning, to reside in the anti-Mullerian hormone receptor II (amhrII). This receptor belongs to the TGF- $\beta$ /BMP superfamily and in humans is known to play a role in Mullerian duct regression in males. The mutation, in exon 9 of amhrII, changes a tyrosine residue in the highly conserved kinase domain to cysteine.

Neumann and co-workers used ENU mutagenesis and high-throughput histologic screening to identify a line of zebrafish that developed testicular germ cell tumors (GCTs) with high penetrance (>80\% incidence in homozygotes by 4 months of age) (Figure 2). They showed that the mutation is dominantly inherited, and causes the development of tumors of primitive, undifferentiated testicular GCTs resembling human seminoma (Figure 3). Like human seminomas, the zebrafish seminomas were sensitive to radiation therapy and underwent apoptosis in response to DNA damage [137]. To identify the molecular nature of the mutation, these investigators developed a haplotype-mapping panel and, using this technique coupled with further high-resolution meiotic mapping, identified a mutation in the Type IB BMP receptor, alk6b/bmpr1bb, as the cause of the zebrafish GCTs [138]. BMPs (Bone Morphogenetic Proteins), members of the TGF- $\beta$ superfamily, play important roles in development and differentiation, but had not been linked to GCTs. Neumann et al. showed that the mutation causes loss of BMP signal transduction, and that BMP signaling is required 
for germ cell differentiation. This work represents the first identification through positional cloning of a cancer predisposition mutation in the zebrafish.

To understand the relevance of BMP signaling to human GCTs, Fustino et al. profiled the state of the BMP pathway in clinical GCT specimens and showed that undifferentiated human GCTs (seminomas and embryonal carcinomas) also lack BMP signaling [139]. This work also identified the miR-200 family of microRNAs as modulators of the BMP pathway, providing an explanation for differential BMP signaling activity in seminomas vs. yolk sac tumors. Collectively these studies identified BMP signaling as a key node in GCT differentiation and a promising target for novel therapies.

The first and only transgenic model of GCTs was identified by Gill et al. In this model, the Simian Virus 40 (SV40) T-antigen (TAg) is driven by the lymphocyte specific tyrosine kinase (lck) promoter from Fugu. Originally intended as a T-cell leukemia model, these fish did not manifest thymic malignancies, but rather testicular GCT. By 36 months, about 20\% of the offspring developed tumors [140]. When comparing the tumors with wild type testis, the GCTs were clearly enlarged and lacked organized seminiferous tubules. Furthermore, the testicular GCTs were predominantly composed of undifferentiated spermatogonial-like germ cells determined by both sorting the cells by size (FACs) and histological analysis (Figure 3) [140]. Expression patterns of human seminoma specific genes were unchanged as compared to zebrafish wildtype testis. Various RAS genes were also sequenced in the zebrafish to identify any de novo mutations that could explain the TGCTs in the fish but none were found.

Finally, the most recent GCT model was identified through a forward genetic ENU screen. The causative mutation is a nonsense mutation in the leucine-rich repeat (LRR)-containing protein Irrc50 [141]. Initially, this forward genetic screen was performed to identify genes involved in ciliary motility. Irrc50 mutants develop a phenotype resembling that of human primary ciliary dyskinesia (PCD). Early in development, the 1rrc50 homozygous mutants develop a curved body axis, dilated pronephric ducts, kidney cysts and severe edema, which ultimately results in embryonic death at 8 days post-fertilization (dpf) [141]. Interestingly, heterozygous 1 rrc 50 mutants display increased incidence of testicular GCT, suggesting a novel tumor suppressor role for lrrc50.

Irrc50 heterozygous mutants display a $90 \%$ GCT penetrance in their $2^{\text {nd }}$ and $3^{\text {rd }}$ years of life [142]. Histological analysis of the tumors found that there were severely reduced numbers of differentiated germ cells, and most of the cells morphologically resembled early spermatogonial cells (Figure 3). These cells also stained positive for phospho-histone $\mathrm{H} 3$ in single cells unlike the wild type testis, which showed reduced staining in clusters. $44.4 \%$ of the tumors examined showed a loss of the Irrc 50 wildtype allele, consistent with a role for Irrc 50 as a tumor suppressor.

This model is, to date, the only one that found mutations in the respective gene in human seminomas [142]. Basten et al. identified LRRC50 nonsense mutations in two pedigrees with family history of seminomas. In a separate analysis of 38 patients with sporadic seminomas, 5 demonstrated heterozygosity for different germline LRRC50 mutations. The 
mutations were shown to be functional nulls by their inability to complement the lethal larval phenotype of Irrc50 mutants. These results establish LRRC5O as the first gene specifically linked to seminoma predisposition in humans. These results prompted an investigation of the possible roles of cilia in germ cell development. In a novel finding, the investigators demonstrated the presence of primary cilia in normal spermatogonia and showed that LRRC50 colocalizes with the axoneme in spermatogonial stem cells, that its expression is cell cycle-regulated and that it colocalizes with condensed chromosomes [142]. These results shed new light on the possible importance of ciliary signaling in germ cell development and germ cell tumorigenesis.

\section{Summary}

Germ cell tumors are among the most common cancers of young people, and the leading cause of cancer death in young men. The wide age range of incidence and histologic diversity of the tumors creates challenges in GCT biology and treatment. While some genomic data are now beginning to point to possible molecular origins of these tumors, the paucity of representative animal models is an impediment to further functional genomic and translational studies.

To date the zebrafish has proved to be a powerful model for understanding the biology of PGC development and migration. While there are important differences between human and fish germ cells, a number of conserved mechanisms have been identified, suggesting that studies in zebrafish can contribute importantly to our understanding of human germ cell biology.

Zebrafish models of human germ cell tumors have also begun to make important contributions. The studies described above have identified several signaling pathways, such as the TGF- $\beta$ /BMP pathway and cilia-mediated signaling, that are directly relevant to human seminomas. The development of seminoma-like tumors in fish transgenic for the known oncogene SV40 large T, and the response of GCTs to DNA-damaging agents, suggests that these models recapitulate important aspects of the oncogenic phenotype of human GCTs.

There are, however, several important caveats that apply to the current models. There is no evidence that these models of GCTs become invasive or malignant, as do some examples of human seminomas. To date, true zebrafish models of ovarian GCT (as opposed to models of impaired maturation of post-meiotic oocytes) have not been described. Reverse genetic models that use gain or loss-of-function approaches and germ cell-specific promoters to test the role of specific GCT candidate genes, at specific developmental stages, remain to be developed. This is a particularly significant gap in current approaches, because it is likely that the ability of germ cells to develop along somatic lineages, as seen in non-seminomas, is limited to specific stages of development in which germ cells retain some pluripotency. In humans, non-seminomas are more resistant to treatment and more likely to metastasize than are seminomas, and are responsible for the majority of deaths from GCT, emphasizing the need for such models. However, there is reason to be optimistic. The great recent progress in the field, with the availability of new promoters, new genome editing techniques and increasing information about the genomic landscape of human GCT, means that the next few 
years promise to see great advances in our understanding of GCT, and better options for GCT patients.

\section{Acknowledgements}

AS was supported by training grant 5T32 CA124334. JFA was supported by a grant RP110394 from the Cancer Prevention and Research Institute of Texas.

\section{References}

1. Houston DW, King ML. Germ plasm and molecular determinants of germ cell fate. Curr Top Dev Biol. 2000; 50:155-81. [PubMed: 10948454]

2. Kosaka K, et al. Spatiotemporal localization of germ plasm RNAs during zebrafish oogenesis. Mech Dev. 2007; 124(4):279-89. [PubMed: 17293094]

3. Raz E. Primordial germ-cell development: the zebrafish perspective. Nat Rev Genet. 2003; 4(9): 690-700. [PubMed: 12951570]

4. Saffman EE, Lasko P. Germline development in vertebrates and invertebrates. Cell Mol Life Sci. 1999; 55(8-9):1141-63. [PubMed: 10442094]

5. Koprunner M, et al. A zebrafish nanos-related gene is essential for the development of primordial germ cells. Genes Dev. 2001; 15(21):2877-85. [PubMed: 11691838]

6. Lai F, King ML. Repressive translational control in germ cells. Mol Reprod Dev. 2013; 80(8):66576. [PubMed: 23408501]

7. Braat AK, et al. Characterization of zebrafish primordial germ cells: morphology and early distribution of vasa RNA. Dev Dyn. 1999; 216(2):153-67. [PubMed: 10536055]

8. Knaut $\mathrm{H}$, et al. Zebrafish vasa RNA but not its protein is a component of the germ plasm and segregates asymmetrically before germline specification. J Cell Biol. 2000; 149(4):875-88. [PubMed: 10811828]

9. Olsen LC, Aasland R, Fjose A. A vasa-like gene in zebrafish identifies putative primordial germ cells. Mech Dev. 1997; 66(1-2):95-105. [PubMed: 9376327]

10. Yoon C, Kawakami K, Hopkins N. Zebrafish vasa homologue RNA is localized to the cleavage planes of 2- and 4-cell-stage embryos and is expressed in the primordial germ cells. Development. 1997; 124(16):3157-65. [PubMed: 9272956]

11. Gruidl ME, et al. Multiple potential germ-line helicases are components of the germ-line-specific $P$ granules of Caenorhabditis elegans. Proc Natl Acad Sci U S A. 1996; 93(24):13837-42. [PubMed: 8943022]

12. Hay B, Jan LY, Jan YN. A protein component of Drosophila polar granules is encoded by vasa and has extensive sequence similarity to ATP-dependent helicases. Cell. 1988; 55(4):577-87. [PubMed: 3052853]

13. Komiya $\mathrm{T}$, et al. Isolation and characterization of a novel gene of the DEAD box protein family which is specifically expressed in germ cells of Xenopus laevis. Dev Biol. 1994; 162(2):354-63. [PubMed: 8150200]

14. Liang L, Diehl-Jones W, Lasko P. Localization of vasa protein to the Drosophila pole plasm is independent of its RNA-binding and helicase activities. Development. 1994; 120(5):1201-11. [PubMed: 8026330]

15. Weidinger $\mathrm{G}$, et al. Identification of tissues and patterning events required for distinct steps in early migration of zebrafish primordial germ cells. Development. 1999; 126(23):5295-307. [PubMed: 10556055]

16. Kierszenbaum AL, Tres LL. Primordial germ cell-somatic cell partnership: a balancing cell signaling act. Mol Reprod Dev. 2001; 60(3):277-80. [PubMed: 11599037]

17. Ying Y, Qi X, Zhao GQ. Induction of primordial germ cells from pluripotent epiblast. ScientificWorldJournal. 2002; 2:801-10. [PubMed: 12806005] 
18. de Sousa Lopes SM, et al. BMP signaling mediated by ALK2 in the visceral endoderm is necessary for the generation of primordial germ cells in the mouse embryo. Genes Dev. 2004; 18(15):183849. [PubMed: 15289457]

19. Lacham-Kaplan O. In vivo and in vitro differentiation of male germ cells in the mouse. Reproduction. 2004; 128(2):147-52. [PubMed: 15280553]

20. Saitou M, Barton SC, Surani MA. A molecular programme for the specification of germ cell fate in mice. Nature. 2002; 418(6895):293-300. [PubMed: 12124616]

21. Tanaka SS, et al. Regulation of expression of mouse interferon-induced transmembrane protein like gene-3, Ifitm3 (mil-1, fragilis), in germ cells. Dev Dyn. 2004; 230(4):651-9. [PubMed: 15254899]

22. Lawson KA, et al. Bmp4 is required for the generation of primordial germ cells in the mouse embryo. Genes Dev. 1999; 13(4):424-36. [PubMed: 10049358]

23. Ying Y, Qi X, Zhao GQ. Induction of primordial germ cells from murine epiblasts by synergistic action of BMP4 and BMP8B signaling pathways. Proc Natl Acad Sci U S A. 2001; 98(14):785862. [PubMed: 11427739]

24. Ying Y, Zhao GQ. Cooperation of endoderm-derived BMP2 and extraembryonic ectoderm-derived BMP4 in primordial germ cell generation in the mouse. Dev Biol. 2001; 232(2):484-92. [PubMed: 11401407]

25. Lange UC, et al. The fragilis interferon-inducible gene family of transmembrane proteins is associated with germ cell specification in mice. BMC Dev Biol. 2003; 3:1. [PubMed: 12659663]

26. Tanaka SS, et al. IFITM/Mil/fragilis family proteins IFITM1 and IFITM3 play distinct roles in mouse primordial germ cell homing and repulsion. Dev Cell. 2005; 9(6):745-56. [PubMed: 16326387]

27. Ohinata Y, et al. Blimp1 is a critical determinant of the germ cell lineage in mice. Nature. 2005; 436(7048):207-13. [PubMed: 15937476]

28. Scholer HR, et al. Oct-4: a germline-specific transcription factor mapping to the mouse t-complex. EMBO J. 1990; 9(7):2185-95. [PubMed: 2357966]

29. Hansis C, Grifo JA, Krey LC. Oct-4 expression in inner cell mass and trophectoderm of human blastocysts. Mol Hum Reprod. 2000; 6(11):999-1004. [PubMed: 11044462]

30. Pesce M, Scholer HR. Oct-4: control of totipotency and germline determination. Mol Reprod Dev. 2000; 55(4):452-7. [PubMed: 10694754]

31. Pesce M, Scholer HR. Oct-4: gatekeeper in the beginnings of mammalian development. Stem Cells. 2001; 19(4):271-8. [PubMed: 11463946]

32. Rajpert-De Meyts E, et al. Developmental expression of POU5F1 (OCT-3/4) in normal and dysgenetic human gonads. Hum Reprod. 2004; 19(6):1338-44. [PubMed: 15105401]

33. Hatano SY, et al. Pluripotential competence of cells associated with Nanog activity. Mech Dev. 2005; 122(1):67-79. [PubMed: 15582778]

34. Yamaguchi S, et al. Nanog expression in mouse germ cell development. Gene Expr Patterns. 2005; 5(5):639-46. [PubMed: 15939376]

35. Payer B, et al. Generation of stella-GFP transgenic mice: a novel tool to study germ cell development. Genesis. 2006; 44(2):75-83. [PubMed: 16437550]

36. Buitrago W, Roop DR. Oct-4: the almighty POUripotent regulator? J Invest Dermatol. 2007; 127(2):260-2. [PubMed: 17228302]

37. Molyneaux KA, et al. Time-lapse analysis of living mouse germ cell migration. Dev Biol. 2001; 240(2):488-98. [PubMed: 11784078]

38. Molyneaux K, Wylie C. Primordial germ cell migration. Int J Dev Biol. 2004; 48(5-6):537-44. [PubMed: 15349828]

39. Wylie C. Germ cells. Curr Opin Genet Dev. 2000; 10(4):410-3. [PubMed: 10889067]

40. Kunwar PS, Siekhaus DE, Lehmann R. In vivo migration: a germ cell perspective. Annu Rev Cell Dev Biol. 2006; 22:237-65. [PubMed: 16774460]

41. Weidinger G, et al. Regulation of zebrafish primordial germ cell migration by attraction towards an intermediate target. Development. 2002; 129(1):25-36. [PubMed: 11782398]

42. Doitsidou M, et al. Guidance of primordial germ cell migration by the chemokine SDF-1. Cell. 2002; 111(5):647-59. [PubMed: 12464177] 
43. Knaut $\mathrm{H}$, et al. A zebrafish homologue of the chemokine receptor $\mathrm{Cxcr} 4$ is a germcell guidance receptor. Nature. 2003; 421(6920):279-82. [PubMed: 12508118]

44. Boldajipour B, Raz E. What is left behind--quality control in germ cell migration. Sci STKE. 2007; 2007(383):pe16. [PubMed: 17456805]

45. Anderson R, et al. The onset of germ cell migration in the mouse embryo. Mech Dev. 2000; 91(1-2):61-8. [PubMed: 10704831]

46. Richardson BE, Lehmann R. Mechanisms guiding primordial germ cell migration: strategies from different organisms. Nat Rev Mol Cell Biol. 2010; 11(1):37-49. [PubMed: 20027186]

47. Gu Y, et al. Steel factor controls primordial germ cell survival and motility from the time of their specification in the allantois, and provides a continuous niche throughout their migration. Development. 2009; 136(8):1295-303. [PubMed: 19279135]

48. Runyan C, et al. Steel factor controls midline cell death of primordial germ cells and is essential for their normal proliferation and migration. Development. 2006; 133(24):4861-9. [PubMed: 17107997]

49. McCoshen JA, McCallion DJ. A study of the primordial germ cells during their migratory phase in Steel mutant mice. Experientia. 1975; 31(5):589-90. [PubMed: 1170085]

50. Buehr M, et al. Proliferation and migration of primordial germ cells in We/We mouse embryos. Dev Dyn. 1993; 198(3):182-9. [PubMed: 8136523]

51. Takahashi H. Juvenile hermaphroditism in the zebrafish, Brachydanio rerio. Bull Fac Fish Hokkaid Univ. 1977; 28:57-65.

52. Uchida $\mathrm{D}$, et al. Oocyte apoptosis during the transition from ovary-like tissue to testes during sex differentiation of juvenile zebrafish. J Exp Biol. 2002; 205(Pt 6):711-8. [PubMed: 11914381]

53. Rodriguez-Mari A, et al. Characterization and expression pattern of zebrafish Anti-Mullerian hormone (Amh) relative to sox9a, sox9b, and cyp19a1a, during gonad development. Gene Expr Patterns. 2005; 5(5):655-67. [PubMed: 15939378]

54. von Hofsten J, Larsson A, Olsson PE. Novel steroidogenic factor-1 homolog (ff1d) is coexpressed with anti-Mullerian hormone (AMH) in zebrafish. Dev Dyn. 2005; 233(2):595-604. [PubMed: 15768398]

55. Wang XG, Orban L. Anti-Mullerian hormone and 11 beta-hydroxylase show reciprocal expression to that of aromatase in the transforming gonad of zebrafish males. Dev Dyn. 2007; 236(5):1329_ 38. [PubMed: 17393497]

56. Sun D, et al. Sox9-related signaling controls zebrafish juvenile ovary-testis transformation. Cell Death Dis. 2013; 4:e930. [PubMed: 24263104]

57. Siegfried KR, Nusslein-Volhard C. Germ line control of female sex determination in zebrafish. Dev Biol. 2008; 324(2):277-87. [PubMed: 18930041]

58. Dranow DB, Tucker RP, Draper BW. Germ cells are required to maintain a stable sexual phenotype in adult zebrafish. Dev Biol. 2013; 376(1):43-50. [PubMed: 23348677]

59. Weidinger G, et al. dead end, a novel vertebrate germ plasm component, is required for zebrafish primordial germ cell migration and survival. Curr Biol. 2003; 13(16):1429-34. [PubMed: 12932328]

60. Slanchev K, et al. Development without germ cells: the role of the germ line in zebrafish sex differentiation. Proc Natl Acad Sci U S A. 2005; 102(11):4074-9. [PubMed: 15728735]

61. Tzung KW, et al. Early depletion of primordial germ cells in zebrafish promotes testis formation. Stem Cell Reports. 2015; 4(1):61-73. [PubMed: 25434820]

62. Houwing $\mathrm{S}$, et al. A role for Piwi and piRNAs in germ cell maintenance and transposon silencing in Zebrafish. Cell. 2007; 129(1):69-82. [PubMed: 17418787]

63. Gill ME, et al. Licensing of gametogenesis, dependent on RNA binding protein DAZL, as a gateway to sexual differentiation of fetal germ cells. Proc Natl Acad Sci U S A. 2011; 108(18): 7443-8. [PubMed: 21504946]

64. Lin Y, et al. Germ cell-intrinsic and -extrinsic factors govern meiotic initiation in mouse embryos. Science. 2008; 322(5908):1685-7. [PubMed: 19074348]

65. Hajkova P, et al. Epigenetic reprogramming in mouse primordial germ cells. Mech Dev. 2002; 117(1-2):15-23. [PubMed: 12204247] 
66. Bullejos M, Koopman P. Spatially dynamic expression of Sry in mouse genital ridges. Dev Dyn. 2001; 221(2):201-5. [PubMed: 11376487]

67. Hacker A, et al. Expression of Sry, the mouse sex determining gene. Development. 1995; 121(6): 1603-14. [PubMed: 7600978]

68. Jeske YW, et al. Expression of a linear Sry transcript in the mouse genital ridge. Nat Genet. 1995; 10(4):480-2. [PubMed: 7670499]

69. Houston CS, et al. The campomelic syndrome: review, report of 17 cases, and follow-up on the currently 17-year-old boy first reported by Maroteaux et al in 1971. Am J Med Genet. 1983; 15(1): 3-28. [PubMed: 6344634]

70. Barrionuevo F, et al. Homozygous inactivation of Sox9 causes complete XY sex reversal in mice. Biol Reprod. 2006; 74(1):195-201. [PubMed: 16207837]

71. Chaboissier MC, et al. Functional analysis of Sox 8 and Sox 9 during sex determination in the mouse. Development. 2004; 131(9):1891-901. [PubMed: 15056615]

72. Anderson EL, et al. Stra8 and its inducer, retinoic acid, regulate meiotic initiation in both spermatogenesis and oogenesis in mice. Proc Natl Acad Sci U S A. 2008; 105(39):14976-80. [PubMed: 18799751]

73. Koubova J, et al. Retinoic acid regulates sex-specific timing of meiotic initiation in mice. Proc Natl Acad Sci U S A. 2006; 103(8):2474-9. [PubMed: 16461896]

74. Bowles J, et al. Retinoid signaling determines germ cell fate in mice. Science. 2006; 312(5773): 596-600. [PubMed: 16574820]

75. Kim S, Bardwell VJ, Zarkower D. Cell type-autonomous and non-autonomous requirements for Dmrt1 in postnatal testis differentiation. Dev Biol. 2007; 307(2):314-27. [PubMed: 17540358]

76. Raymond CS, et al. Dmrt1, a gene related to worm and fly sexual regulators, is required for mammalian testis differentiation. Genes Dev. 2000; 14(20):2587-95. [PubMed: 11040213]

77. Matson CK, et al. DMRT1 prevents female reprogramming in the postnatal mammalian testis. Nature. 2011; 476(7358):101-4. [PubMed: 21775990]

78. Lindeman RE, et al. Sexual cell-fate reprogramming in the ovary by DMRT1. Curr Biol. 2015; 25(6):764-71. [PubMed: 25683803]

79. Frazier, AL.; Amatruda, JF. Germ Cell Tumors. In: Fisher, DE.; Nathan, D.; Look, AT., editors. Nathan and Oski's Textbook of Pediatric Hematology-Oncology. Elsevier; London: 2009.

80. Oosterhuis JW, Looijenga LH. Testicular germ-cell tumours in a broader perspective. Nat Rev Cancer. 2005; 5(3):210-22. [PubMed: 15738984]

81. Poynter JN, Amatruda JF, Ross JA. Trends in incidence and survival of pediatric and adolescent patients with germ cell tumors in the United States, 1975 to 2006. Cancer. 2010; 116(20):4882-91. [PubMed: 20597129]

82. Trabert B, et al. International patterns and trends in testicular cancer incidence, overall and by histologic subtype, 1973-2007. Andrology. 2015; 3(1):4-12. [PubMed: 25331326]

83. Jacobsen R, et al. Trends in testicular cancer incidence in the Nordic countries, focusing on the recent decrease in Denmark. Int J Androl. 2006; 29(1):199-204. [PubMed: 16371112]

84. Ross JA, et al. Genomic imprinting of H19 and insulin-like growth factor-2 in pediatric germ cell tumors. Cancer. 1999; 85(6):1389-94. [PubMed: 10189147]

85. Schneider DT, et al. Multipoint imprinting analysis indicates a common precursor cell for gonadal and nongonadal pediatric germ cell tumors. Cancer Res. 2001; 61(19):7268-76. [PubMed: 11585765]

86. Palmer RD, et al. Pediatric malignant germ cell tumors show characteristic transcriptome profiles. Cancer research. 2008; 68(11):4239-47. [PubMed: 18519683]

87. Williams SD, et al. Treatment of disseminated germ-cell tumors with cisplatin, bleomycin, and either vinblastine or etoposide. N Engl J Med. 1987; 316(23):1435-40. [PubMed: 2437455]

88. Einhorn LH, Donohue JP. Improved chemotherapy in disseminated testicular cancer. The Journal of urology. 1977; 117(1):65-9. [PubMed: 63574]

89. Einhorn LH. Chemotherapeutic and surgical strategies for germ cell tumors. Chest Surg Clin N Am. 2002; 12(4):695-706. [PubMed: 12471872] 
90. Osanto S, et al. Long-term effects of chemotherapy in patients with testicular cancer. Journal of clinical oncology : official journal of the American Society of Clinical Oncology. 1992; 10(4): 574-9. [PubMed: 1372350]

91. Bokemeyer C, et al. Evaluation of long-term toxicity after chemotherapy for testicular cancer. Journal of clinical oncology : official journal of the American Society of Clinical Oncology. 1996; 14(11):2923-32. [PubMed: 8918489]

92. Bosl GJ, et al. Increased plasma renin and aldosterone in patients treated with cisplatin-based chemotherapy for metastatic germ-cell tumors. Journal of clinical oncology : official journal of the American Society of Clinical Oncology. 1986; 4(11):1684-9. [PubMed: 3021923]

93. Hansen SW, et al. Long-term effects on renal function and blood pressure of treatment with cisplatin, vinblastine, and bleomycin in patients with germ cell cancer. Journal of clinical oncology : official journal of the American Society of Clinical Oncology. 1988; 6(11):1728-31. [PubMed: 2460594]

94. Hansen PV, Hansen SW. Gonadal function in men with testicular germ cell cancer: the influence of cisplatin-based chemotherapy. European urology. 1993; 23(1):153-6. [PubMed: 8386643]

95. Hansen SW, Berthelsen JG, von der Maase H. Long-term fertility and Leydig cell function in patients treated for germ cell cancer with cisplatin, vinblastine, and bleomycin versus surveillance. Journal of clinical oncology : official journal of the American Society of Clinical Oncology. 1990; 8(10):1695-8. [PubMed: 1698935]

96. Huddart RA, et al. Cardiovascular disease as a long-term complication of treatment for testicular cancer. Journal of clinical oncology : official journal of the American Society of Clinical Oncology. 2003; 21(8):1513-23. [PubMed: 12697875]

97. Strumberg D, et al. Evaluation of long-term toxicity in patients after cisplatin-based chemotherapy for non-seminomatous testicular cancer. Annals of oncology : official journal of the European Society for Medical Oncology / ESMO. 2002; 13(2):229-36. [PubMed: 11885999]

98. Berger CC, et al. Endocrinological late effects after chemotherapy for testicular cancer. British journal of cancer. 1996; 73(9):1108-14. [PubMed: 8624272]

99. Bissett D, et al. Long-term sequelae of treatment for testicular germ cell tumours. British journal of cancer. 1990; 62(4):655-9. [PubMed: 2171622]

100. Gietema JA, et al. Long-term follow-up of cardiovascular risk factors in patients given chemotherapy for disseminated nonseminomatous testicular cancer. Ann Intern Med. 1992; 116(9):709-15. [PubMed: 1558341]

101. Teutsch C, Lipton A, Harvey HA. Raynaud's phenomenon as a side effect of chemotherapy with vinblastine and bleomycin for testicular carcinoma. Cancer Treat Rep. 1977; 61(5):925-6. [PubMed: 70274]

102. Vogelzang NJ, et al. Raynaud's phenomenon: a common toxicity after combination chemotherapy for testicular cancer. Ann Intern Med. 1981; 95(3):288-92. [PubMed: 6168223]

103. Boyer M, et al. Lack of late toxicity in patients treated with cisplatin-containing combination chemotherapy for metastatic testicular cancer. Journal of clinical oncology : official journal of the American Society of Clinical Oncology. 1990; 8(1):21-6. [PubMed: 1688614]

104. Siviero-Miachon AA, Spinola-Castro AM, Guerra-Junior G. Adiposity in childhood cancer survivors: insights into obesity physiopathology. Arq Bras Endocrinol Metabol. 2009; 53(2):190200. [PubMed: 19466212]

105. Siviero-Miachon AA, Spinola-Castro AM, Guerra-Junior G. Detection of metabolic syndrome features among childhood cancer survivors: a target to prevent disease. Vasc Health Risk Manag. 2008; 4(4):825-36. [PubMed: 19065999]

106. Glendenning JL, et al. Long-term neurologic and peripheral vascular toxicity after chemotherapy treatment of testicular cancer. Cancer. 116(10):2322-31. [PubMed: 20225230]

107. Travis LB, et al. Risk of second malignant neoplasms among long-term survivors of testicular cancer. Journal of the National Cancer Institute. 1997; 89(19):1429-39. [PubMed: 9326912]

108. Travis LB, et al. Second cancers among 40,576 testicular cancer patients: focus on long-term survivors. Journal of the National Cancer Institute. 2005; 97(18):1354-65. [PubMed: 16174857] 
109. van Echten $\mathrm{J}$, et al. No recurrent structural abnormalities apart from i(12p) in primary germ cell tumors of the adult testis. Genes, chromosomes \& cancer. 1995; 14(2):133-44. [PubMed: 8527395]

110. Tian Q, et al. Activating c-kit gene mutations in human germ cell tumors. Am J Pathol. 1999; 154(6):1643-7. [PubMed: 10362788]

111. Looijenga LH, et al. Stem cell factor receptor (c-KIT) codon 816 mutations predict development of bilateral testicular germ-cell tumors. Cancer Res. 2003; 63(22):7674-8. [PubMed: 14633689]

112. Kemmer K, et al. KIT mutations are common in testicular seminomas. Am J Pathol. 2004; 164(1): 305-13. [PubMed: 14695343]

113. Hoei-Hansen CE, et al. Ovarian dysgerminomas are characterised by frequent KIT mutations and abundant expression of pluripotency markers. Mol Cancer. 2007; 6:12. [PubMed: 17274819]

114. Coffey J, et al. Somatic KIT mutations occur predominantly in seminoma germ cell tumors and are not predictive of bilateral disease: report of 220 tumors and review of literature. Genes Chromosomes Cancer. 2008; 47(1):34-42. [PubMed: 17943970]

115. Hersmus R, et al. Prevalence of c-KIT mutations in gonadoblastoma and dysgerminomas of patients with disorders of sex development (DSD) and ovarian dysgerminomas. PloS one. 2012; 7(8):e43952. [PubMed: 22937135]

116. Ganguly S, et al. Detection of preferential NRAS mutations in human male germ cell tumors by the polymerase chain reaction. Genes Chromosomes Cancer. 1990; 1(3):228-32. [PubMed: 1964583]

117. Mulder MP, et al. Frequent occurrence of activated ras oncogenes in seminomas but not in nonseminomatous germ cell tumors. Recent results in cancer research. Fortschritte der Krebsforschung. Progres dans les recherches sur le cancer. 1991; 123:125-31. [PubMed: 1660618]

118. Moul JW, Theune SM, Chang EH. Detection of RAS mutations in archival testicular germ cell tumors by polymerase chain reaction and oligonucleotide hybridization. Genes Chromosomes Cancer. 1992; 5(2):109-18. [PubMed: 1381946]

119. Olie RA, et al. N- and KRAS mutations in primary testicular germ cell tumors: incidence and possible biological implications. Genes Chromosomes Cancer. 1995; 12(2):110-6. [PubMed: 7535083]

120. Wang L, et al. Novel somatic and germline mutations in intracranial germ cell tumours. Nature. 2014; 511(7508):241-5. [PubMed: 24896186]

121. Honecker F, et al. Microsatellite instability, mismatch repair deficiency, and BRAF mutation in treatment-resistant germ cell tumors. Journal of clinical oncology : official journal of the American Society of Clinical Oncology. 2009; 27(13):2129-36. [PubMed: 19289622]

122. Brabrand $\mathrm{S}$, et al. Exome sequencing of bilateral testicular germ cell tumors suggests independent development lineages. Neoplasia. 2015; 17(2):167-74. [PubMed: 25748235]

123. Litchfield $\mathrm{K}$, et al. Whole-exome sequencing reveals the mutational spectrum of testicular germ cell tumours. Nat Commun. 2015; 6:5973. [PubMed: 25609015]

124. Kanetsky PA, et al. Common variation in KITLG and at 5q31.3 predisposes to testicular germ cell cancer. Nature genetics. 2009; 41(7):811-5. [PubMed: 19483682]

125. Rapley EA, et al. A genome-wide association study of testicular germ cell tumor. Nature genetics. 2009; 41(7):807-10. [PubMed: 19483681]

126. Turnbull C, et al. Variants near DMRT1, TERT and ATF7IP are associated with testicular germ cell cancer. Nature genetics. 2010; 42(7):604-7. [PubMed: 20543847]

127. Kratz CP, et al. Variants in or near KITLG, BAK1, DMRT1, and TERT-CLPTM1L predispose to familial testicular germ cell tumour. J Med Genet. 2011; 48(7):473-6. [PubMed: 21617256]

128. Lessel D, et al. Replication of genetic susceptibility loci for testicular germ cell cancer in the Croatian population. Carcinogenesis. 2012; 33(8):1548-52. [PubMed: 22745383]

129. Karlsson R, et al. Investigation of six testicular germ cell tumor susceptibility genes suggests a parent-of-origin effect in SPRY4. Hum Mol Genet. 2013

130. Chung CC, et al. Meta-analysis identifies four new loci associated with testicular germ cell tumor. Nature genetics. 2013; 45(6):680-5. [PubMed: 23666239]

Adv Exp Med Biol. Author manuscript; available in PMC 2016 July 25. 
131. Ruark E, et al. Identification of nine new susceptibility loci for testicular cancer, including variants near DAZL and PRDM14. Nature genetics. 2013; 45(6):686-9. [PubMed: 23666240]

132. Stevens LC. Experimental production of testicular teratomas in mice of strains $129, \mathrm{~A} / \mathrm{He}$, and their F1 hybrids. Journal of the National Cancer Institute. 1970; 44(4):923-9. [PubMed: 11515059]

133. Youngren KK, et al. The Ter mutation in the dead end gene causes germ cell loss and testicular germ cell tumours. Nature. 2005; 435(7040):360-4. [PubMed: 15902260]

134. Krentz AD, et al. Interaction between DMRT1 function and genetic background modulates signaling and pluripotency to control tumor susceptibility in the fetal germ line. Dev Biol. 2013

135. Krentz AD, et al. The DM domain protein DMRT1 is a dose-sensitive regulator of fetal germ cell proliferation and pluripotency. Proc Natl Acad Sci U S A. 2009; 106(52):22323-8. [PubMed: 20007774]

136. Morinaga $\mathrm{C}$, et al. The hotei mutation of medaka in the anti-Mullerian hormone receptor causes the dysregulation of germ cell and sexual development. Proc Natl Acad Sci U S A. 2007; 104(23):9691-6. [PubMed: 17535919]

137. Neumann JC, et al. Identification of a heritable model of testicular germ cell tumor in the zebrafish. Zebrafish. 2009; 6(4):319-27. [PubMed: 20047465]

138. Neumann JC, et al. Mutation in the type IB bone morphogenetic protein receptor Alk6b impairs germ-cell differentiation and causes germ-cell tumors in zebrafish. Proceedings of the National Academy of Sciences of the United States of America. 2011; 108(32):13153-8. [PubMed: 21775673]

139. Fustino N, et al. Bone morphogenetic protein signalling activity distinguishes histological subsets of paediatric germ cell tumours. Int J Androl. 2011; 34(4 Pt 2):e218-33. [PubMed: 21696393]

140. Gill JA, et al. Enforced expression of Simian virus 40 large T-antigen leads to testicular germ cell tumors in zebrafish. Zebrafish. 2010; 7(4):333-41. [PubMed: 21158563]

141. van Rooijen E, et al. LRRC50, a conserved ciliary protein implicated in polycystic kidney disease. J Am Soc Nephrol. 2008; 19(6):1128-38. [PubMed: 18385425]

142. Basten SG, et al. Mutations in LRRC50 predispose zebrafish and humans to seminomas. PLoS Genet. 2013; 9(4):e1003384. [PubMed: 23599692] 

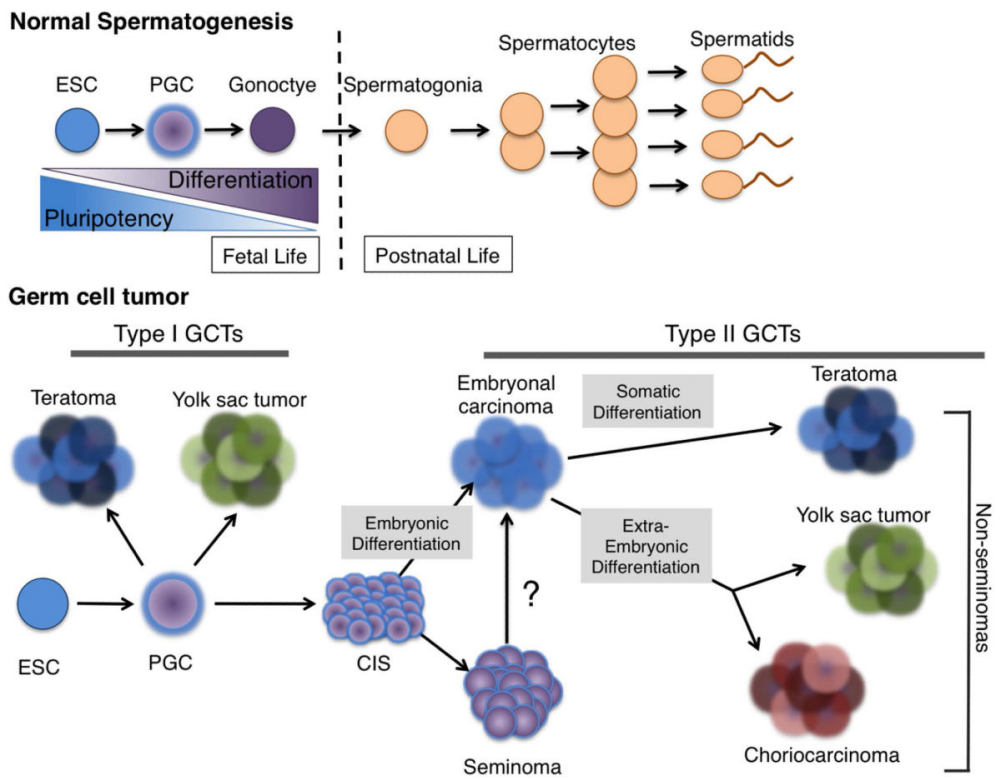

Figure 1. Mammalian spermatogenesis and human germ cell tumor (GCT) histological classification

The transition of primordial germ cells from embryonic stem cells to gonocytes is facilitated by increased expression of germ cell specific genes and decreased expression of embryonic pluripotency genes. In humans, sex chromosomes dictate the fate of a gonocyte; in the testis self-renewing spermatogonial stem cells give rise to progeny that undergo meiosis to produce mature sperm. Germ cell tumors arise from primoridal germ cells (PGCs). Type I GCTs are generally seen in neonates and young children and include Teratomas and Yolk Sac Tumors. Type II GCTs occur in adolescents and adults and may proceed through a carcinoma in situ (CIS) precursor (also known as Intratubular Germ Cell Neoplasia). CIS cells can give rise to both Seminoma and Non-Seminoma, the stem cell component of which is Embryonal Carcinoma (EC). EC may undergo somatic differentiation into Teratomas, containing derivatives of ectoderm, mesoderm and endoderm. Alternatively EC cells may differentiate into GCTs resembling extraembryonic tissues, such as Yolk Sac Tumor and Choriocarcinoma. Mixed tumors containing both seminoma and non-seminoma components also occur. 
a

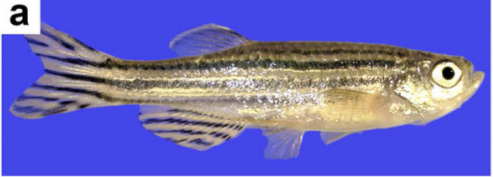

b

C

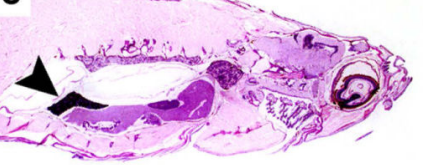

d

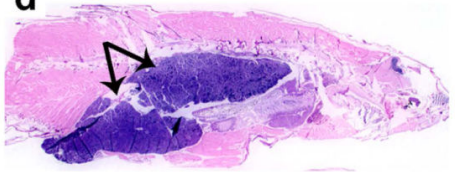

Figure 2. Testicular GCT in bmpr1bb mutant zebrafish

Mutants develop GCTs because of impaired germ-cell differentiation. Compared with adult wild-type males (a and c) (arrowhead: normal testis), adult bmpr1bb males display abdominal distension and marked testicular enlargement (b and d) (arrow: testicular tumor). Modified with permission from Neumann et al., 2011 


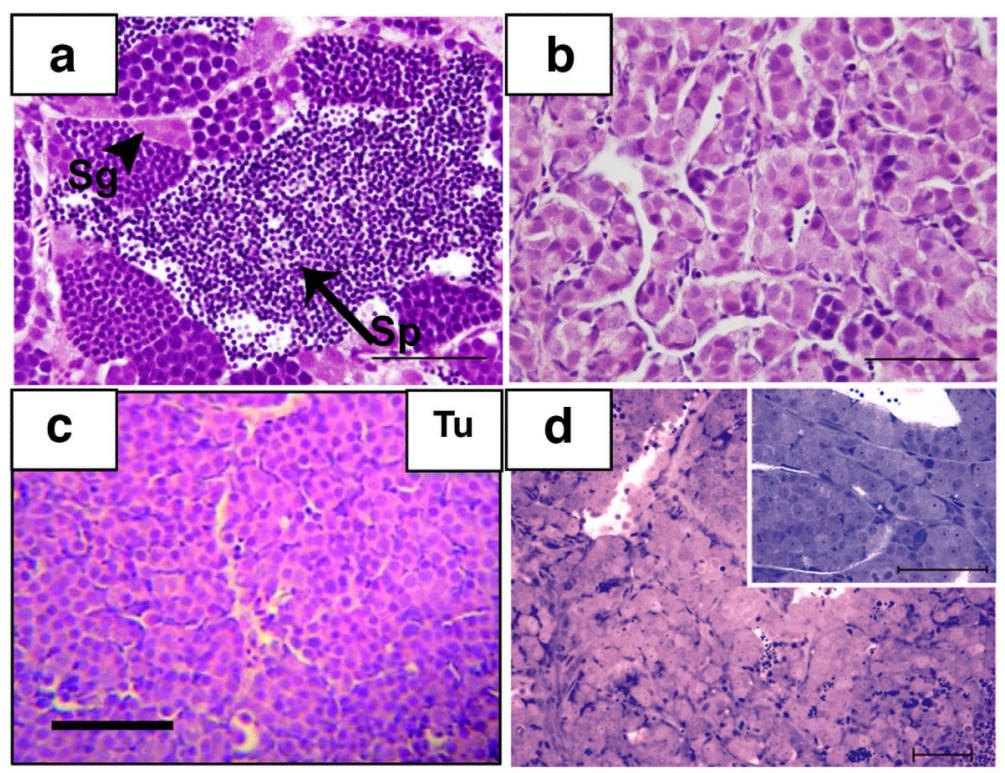

Figure 3. Zebrafish germ cell tumor models exhibit histologic similarity

a, normal testis. The testis consists of cysts or lobules of spermatogenic cells surrounded by a basement membrane and somatic cells. Small clusters of spermatogonia are seen adjacent to the basement membrane (arrowheads). Successive stages of differentiation are also evident, including primary and secondary spermatocytes, spermatids and mature spermatozoa. b, Germ cell tumor in a bmpr $1 b b$ mutant testis, showing loss of differentiation and an excess of primitive, spermatogonial-like cells. c, Testicular germ cell tumor from the Tg(flck:TAg) T24 line. Tu: tumor. d, testicular GCT in a $1 r r c 50^{H 255 h}$ fish. Two magnifications of the same tumor shown (largest in insert), with loss of differentiated germ cells in the tumor. Scale bars: 50 microns. (a,b: modified with permission from Neumann et al., 2011. c, modified with permission from Gill et al., 2010. d, modified from Basten et al., 2013.) 